\title{
ALFRED ADLER (1870-1937): Uma breve biografia
}

\author{
ALFRED ADLER (1870-1937): A short biography \\ ALFRED ADLER (1870-1937): Una breve biografía
}

\author{
Daniela Leal* \\ Universidade de São Paulo - USP, São Paulo, São Paulo, Brasil \\ Marina Massimi** \\ Universidade de São Paulo - USP, São Paulo, São Paulo, Brasil
}

\begin{abstract}
RESUMO
Este artigo objetiva apresentar uma breve biografia do médico psiquiatra Alfred Adler, desde seu nascimento até o desenvolvimento de sua teoria, a Psicologia Individual, com 0 intuito de apontar algumas de suas contribuições para o desenvolvimento da área da Psicologia, assim como a relação observada entre a criação dos conceitos-chave de sua teoria com suas próprias vivências, ao longo de seus 67 anos de vida. Para tanto, optou-se por uma pesquisa de cunho histórico, seguindo a abordagem historiográfica proposta por De Certeau (2010). Por fim, observou-se que, tanto a atitude adotada frente à vida quanto a construção teórica da Psicologia Individual se constituíram por intermédio, primeiro, da harmonia existente entre os fatos vivenciados durante a infância de Adler: estreito círculo familiar e condições de saúde enfrentadas nos 5 primeiros anos de vida (raquitismo, pneumonia). Segundo que, um dos seus principais conceitos, o de sentimento de comunidade, foi sendo construído desde as primeiras relações estabelecidas com os colegas de rua e da escola, passando pelo relacionamento que estabelecia com seus pacientes no consultório e, chegando, à preocupação com a reconstrução social da educação de seu país.
\end{abstract}

Palavras-chave: Alfred Adler, História, Psicologia Individual.

\section{ABSTRACT}

The aim of this article is to provide a brief biography of the psychiatrist Alfred Adler, from his birth to the development of his theory, Individual Psychology, in order to point out some of his contributions to the development of the field of psychology, as well as the relationship between the creation of the key concepts of his theory and his own experiences, over his 67 years of life. Therefore, a historical nature of research was chosen, following the historiographical approach proposed by De Certeau (2010). Finally, it was observed that both the adopted attitude to life and the theoretical construction of Individual Psychology are formed through firstly, the harmony existing between the experienced facts during Adler's childhood: narrow family circle and health conditions faced in the first five years of life (rickets, pneumonia); and secondly, through one of his main concepts, the sense of community, which was built from the first 
relationships established with street peers and schoolmates, through the relationship established with patients in the office, reaching the concern with the social reconstruction of education in his country.

Keywords: Alfred Adler, History, Individual Psychology.

\section{RESUMEN}

En este artículo, se objetiva presentar una breve biografía del médico psiquiatra Alfred Adler, desde su nacimiento hasta el desarrollo de su teoría, la Psicología Individual, con la pretensión de señalar algunas de sus contribuciones para el desarrollo del área de Psicología, como también la relación observada entre la creación de los conceptos-clave de su teoría con sus propias vivencias, a lo largo de sus 67 años de vida. Para tanto, se optó por una investigación histórica, siguiendo el abordaje historiográfico propuesto por De Certeau (2010). Por fin, se observó que, tanto la aptitud adoptada frente a la vida como la construcción teórica de la Psicología Individual se constituyeron por intermedio, primero, de la harmonía existente entre los hechos vivenciados durante la infancia de Adler: estrecho círculo familiar y condiciones de salud enfrentadas en los 5 primeros años de vida (raquitismo, pulmonía); segundo que, uno de sus principales conceptos, el de sentimiento de comunidad, fue siendo construido desde las primeras relaciones establecidas con los compañeros de la calle y de la escuela, pasando por el relacionamiento que establecía con sus pacientes en el consultorio y, llegando, a la preocupación con la reconstrucción social de la educación de su país.

Palabras-Clave: Alfred Adler, Historia, Psicología Individual.

\section{I ntrodução}

Entre os anos de 1898 e 1937 destacou-se na Psicologia, inicialmente na Psicanálise, juntamente com Freud, e posteriormente na Psicologia Individual, como ele próprio denominou, as pesquisas e as concepções teóricas do médico austríaco Alfred Adler (1870-1937).

Uma escola de pensamento e de clínica cujos princípios pautavam-se em uma Psicologia que considerava a personalidade como única, indivisível ou, como descrito pelo próprio Adler (1968a), uma Psicologia que se dedicava ao estudo da unidade do indivíduo para compreensão de sua totalidade. Ou, como descrito por Stein e Edwards (1998), uma Psicologia que orientava os seres humanos a serem capazes de cooperar pela convivência com os demais, esforçando-se para o auto-aperfeiçoamento, a auto-realização e a contribuição para o bem-estar comum.

E, nesse sentido, o papel da Psicologia Individual, segundo Adler (1968a), seria de provar esta unidade em cada indivíduo; em seu consciente e inconsciente; em cada expressão de sua personalidade. Consequentemente, o psicólogo individual trabalharia a relação entre o indivíduo e o seu meio, em um mundo que inclui o próprio corpo do indivíduo, suas funções corporais e mentais.

Posto isso, objetiva-se neste artigo apresentar uma breve biografia do médico psiquiatra Alfred Adler, desde seu nascimento até o 
desenvolvimento de sua teoria, a Psicologia Individual, com o intuito de apontar algumas de suas contribuições para o desenvolvimento da Psicologia, assim como evidenciar a relação observada entre a criação dos seus conceitos-chave com suas próprias vivências, ao longo de seus 67 anos de vida. Para tanto, optou-se por uma pesquisa de cunho histórico, seguindo a abordagem historiográfica proposta por De Certeau (2010).

\section{Do nascimento aos primeiros anos pós-formação em Medicina}

Em 07 de fevereiro de 1870 nasceu Alfred Adler, em Penzing - na época uma aldeia, atualmente uma parte do 15 o Distrito da cidade de Viena, na Áustria - , em uma casa que era, segundo Bottome (1952), literalmente, a última da cidade. Durante toda a sua infância, sua família mudou-se de residência várias vezes, intercalando-se entre os subúrbios ao oeste ou ao sul de Viena - o que, para Carl Furtmüller (1968), foi de fundamental importância para o desenvolvimento da personalidade de Adler.

Seus pais, apesar de viverem em Viena desde o matrimônio, eram ambos oriundos de outro país: sua mãe era húngara e seu pai nasceu em Burgenland, que antes de 1918 era parte da Hungria e depois passou a ser parte da Áustria (Bottome, 1952). O pai de Adler era um comerciante de grãos e na época de seu nascimento a família estava bem economicamente, ao contrário do que seriam os anos vindouros: "os Adler eram uma família feliz, independente e abastada" (Bottome, 1952, p. 47).

Desde o princípio, Adler era o filho favorito de seu pai, "um homem de personalidade livre e feliz, tremendamente orgulhoso", que insistia que os filhos deviam gozar de "uma grande liberdade pessoal, evitando tanto castigos quanto carícias" (Bottome, 1952, p. 50). Dele, Adler herdou as qualidades mentais e espirituais. Da mãe, herdou as características físicas: ombros largos, membros pequenos, muito forte, com uma frente sólida de pensador e com olhos brilhantes e cheios de vida. "Todo o mistério da personalidade de Adler encontrava-se em seus olhos; eles olhavam, protegidos por sobrancelhas espessas, como se compreendessem a alma do homem, mas guardando para si o que dizer do que vislumbrava" (Bottome, 1952, p. 49).

Ao contrário do relacionamento próximo que tinha com o pai, Adler sentia-se menos ligado à mãe, por crer que ela tinha preferência por seu irmão mais velho. Para Adler (como citado por Von Perfall, 1999), o filho primogênito, geralmente, era o que recebia a maior quantidade de atenção e carinho, bem como era o que tinha mais experiência e, consequentemente, era o mais poderoso e em quem os pais depositavam toda a confiança. Nesse sentido, por ser 0 
terceiro filho, de quatro homens e duas mulheres, Adler sentia-se colocado à sombra de seu irmão mais velho, considerado exemplar e "um típico primeiro filho". Em suas próprias palavras, citadas por Bottome (1952): "Meu irmão mais velho era a única pessoa com que não cheguei a me dar bem; ele nunca participava de nossas brincadeiras" (p. 53), "Sempre foi muito superior [...]" (p. 48).

Depois do nascimento de seu irmão mais novo, Richard, Adler sentiuse deixado de lado, ainda mais. Isto porque, seu irmão mais novo nasceu quando ele tinha aproximadamente quatro anos de idade e, segundo suas próprias palavras, "antes que ele nascera, não tinha a menor dúvida que me mimavam e cuidavam-me com a máxima aplicação, por causa da minha enferma debilidade. Estou certo que, a partir da sua chegada ao mundo, tive que me contentar com uma atenção menor" (Adler como citado em Bottome, 1952, p. 52). Com o tempo, entretanto, até mesmo devido à difícil condição financeira pela qual passava sua família nesse período, Adler guiou e fortaleceu "seu irmão mais novo de todas as formas e, durante toda a sua vida, o ajudou tanto material quanto moralmente" (p. 49).

Com relação a enfermidade citada, Adler referia-se ao raquitismo, desde o nascimento, e, posteriormente, a uma grave pneumonia que quase o levou à morte, aos 5 anos de idade. Especificamente ao raquitismo, uma das lembranças mais pontuais de Adler (como citado em Bottome, 1952) refere-se ao dia em que ele e seu irmão estavam sentados em um banco ao lado de casa: "Meu irmão mais velho, completamente são, estava sentado na minha frente. Ele podia correr, saltar e mover-se sem quase nenhum esforço, enquanto que para mim, o menor movimento exigia esforço e fadiga" (p. 52). Já, com relação à pneumonia, ele descreve:

Uma pneumonia que sofri com a idade de cinco anos, proporcionou minha precoce compreensão da morte em si [...]. O médico, chamado urgentemente, disse a meu pai que não valia a pena se incomodar preocupando-se comigo, já que não tinha nenhuma esperança de sobreviver. Invadiu-me um medo e, alguns dias depois, uma vez recuperado, decidiu definitivamente ser médico, para dispor de uma defesa mais eficaz contra o perigo da morte e de armas para combatê-la, superiores as do meu médico (Adler como citado em Bottome, 1952, pp. 54-55).

Nos primeiros anos escolares, Adler não era precisamente um dos melhores alunos. Ele próprio afirmava que, "na maioria das disciplinas não ia além da mediocridade, sem alcançar qualquer sucesso notável" (como citado em Bottome, 1952, p. 60); principalmente nas matérias relacionadas à matemática. Tanto que, uma vez, um de seus professores de aritmética sugeriu ao seu pai 
que o tirasse da escola para ser aprendiz de sapateiro, porque acreditava que Adler nunca se formaria. Desafiado, Adler mostrou ao professor que era capaz.

Durante um tempo, foi incapaz de reunir a coragem necessária para levantar à mão. Supunha que toda a classe riria à gargalhadas diante de sua audácia, pretendendo resolver um problema difícil, cuja solução os demais acabavam de fracassar, pois davam por sabido que ele era o pior estudante de toda a classe de aritmética e, para o espírito orgulhoso de [Adler], era insuportável ser objeto de insultos e vaias. Contudo, quando um dos melhores alunos da classe fracassou em sua vez, [Adler] percebeu que estava de pé, levantando sua mão. Seus piores temores converteram-se em realidade quando o professor e os alunos caíram na gargalhada diante de tamanha presunção; mas, uma vez em pé, manteve seu espírito de lutador. Explicou a solução que, por súbita inspiração, acabara de encontrar e, para seu alívio, ele podia ouvir triunfante que tinha atingido a resposta (Bottome, 1952, p. 61).

A partir desse momento, Adler nunca mais teve dificuldades com as matemáticas ou com qualquer outra disciplina. Pelo contrário, tornouse um "verdadeiro prodígio, resolvendo problemas com a mesma velocidade com que os direcionavam" (Bottome, 1952, p. 61). Vale destacar que, o sucesso notável na vida escolar de Adler dava-se, também e principalmente, pelo grande número e pela variedade de amizades que estabeleceu, com pessoas de todas as classes e condições, dentro e fora da escola. "Adler dedicou toda a sua mocidade à aprender a viver o mais plenamente possível e a como responder e a reagir entre seus semelhantes" (p. 61).

Ainda como escreve Bottome (1952), Adler "sempre se propôs a ser médico; sabia que seu pai aprovava e mantinha sua ambição com entusiasmo. Absorvia seus livros com um propósito definido e uma concentração cada vez maior" ( p. 65), dedicando-se "a ler seriamente e com afinco tudo quanto lhe parecia servir ao seu objetivo final" ( $p$. 65): tornar-se médico.

Durante o curso de Medicina, na Universidade de Viena, apesar de se ter poucos relatos sobre seu relacionamento com os professores ou com os estudos, sabe-se que Adler tinha como referência o clínico geral Hermann Nothnagel, um especialista que defendia que os médicos deveriam considerar o paciente sempre como um todo, não como um órgão isolado ou uma doença isolada. Para Nothnagel se a pessoa queria ser um bom médico, deveria ser uma pessoa amável. $E$, foi exatamente "este Blick aufs Ganze (visão dirigida ao todo) que caracterizou Adler como praticante, como psiquiatra e como filósofo" (Furtmüller, 1968, p. 289).

Nesse período, Adler dedicou-se, também, ao estudo aprofundado da história da Psicologia: "começou a formar a opinião sobre a qual fundamentaria todos os seus estudos e descobertas posteriores" 
(Bottome, 1952, p. 65), principalmente "o descobrimento do poder do ser humano para transformar o 'menos' em 'mais' [sentimento de inferioridade-compensação]" (p. 66).

Outro ponto marcante na vida de estudante de Medicina e que influenciou em suas escolhas futuras, foi a amizade com integrantes do grupo socialista da Universidade de Viena. Como um jovem doutor, se uniu ao grupo e comparecia às reuniões de debate e, algumas vezes, às grandes reuniões populares, geralmente em companhia da estudante russa, Raissa Timofeyewna Epstein, que logo se tornou a senhora Alfred Adler. A participação de Adler, segundo Furtmüller (1968), não era de um orador ou de alguém que quisesse polemizar. Adler era um ouvinte, um observador. Apesar de não ser ativo politicamente, a concepção sociológica na qual pautava-se, o marxismo, exerceu influência decisiva em todo o desenvolvimento de seu pensamento.

Em 1896, ano seguinte a obtenção do diploma de Medicina, Adler estabeleceu-se no bairro de Praterstrasse, juntamente com sua esposa Raissa, onde abriu seu consultório e passou à atender, em sua maioria, judeus e pessoas de classe média baixa, assim como os garçons, os artistas dos espetáculos do Prater, o famoso parque de diversões de Viena, que estava a cerca de seu consultório. Por ganharem a vida exibindo sua força e suas habilidades corporais extraordinárias, a maioria dessas pessoas sofria de padecimentos físicos. Ao atender tais pacientes, boa parte de suas observações o levaram, futuramente, a sua concepção de supercompensação e, posteriormente, na publicação do livro Studie über Minderwertigkeit von Organen (Estudo sobre a inferioridade dos órgãos).

Adler administrava a ciência aos seus pacientes, segundo Furtmüller (1968), "como fazer ovos mexidos", isto é, quando dispunha de um termo científico e de um termo popular, nunca utilizava o primeiro com seus pacientes, somente o segundo. Sempre dava a família e ao próprio paciente a interpretação clara do diagnóstico e do tratamento, pois "sabia o que a visita do médico significava para a moral do paciente e assegurando-se de deixá-lo mais alegre do que como o havia encontrado. Contava pequenas histórias da vida diária que colocavam o paciente em contato com o mundo externo; sempre tinha uma pequena piada [...]" (Furtmüller, 1968, p. 292).

Os casos mais expressivos atendidos por Adler, no consultório, envolviam quase sempre os depressivos mentais; o quais, por muitas vezes, os salvava da miséria e/ou do suicídio. Mas, também, desenvolvia com facilidade e simplicidade o trato com as crianças: "Toda Viena gostava de assistir às suas clínicas infantis públicas e o Volksheim ('Casa do Povo'), onde as organizava, estava sempre cheio" (Bottome, 1952, p. 145).

Destaca-se nesse período (1898 a 1909), também, o nascimento de seus quatro filhos: Valentine, Alexandra, Kurt e Nelly. Tal fato 
contribuiu para a compreensão de Adler a respeito do desenvolvimento do caráter infantil, pois, de acordo com Furtmüller (1968), a sua vida familiar serviu de estímulo e como parte do material favorável as suas teorias sobre educação e condução infantil, principalmente as relacionadas à influência da mãe na formação do caráter dos filhos e à constelação familiar. De acordo com Bottome (1952), Adler conseguiu, apesar de se dedicar cerca de 16 horas por dia ao trabalho, enriquecer a vida de seus filhos e ajudá-los significativamente, principalmente ao relacionar-se com eles diferentemente do relacionamento que obteve com seu pai, que não primava pela demonstração de carinho.

\section{A relação com Freud}

O encontro de Adler com Freud foi decisivo tanto na vida de Adler quanto na história da Psicoterapia e da Psicologia, isto porque, para Adler, a forma como eram tratadas as desordens nervosas naquela época, de maneira simples e sintomática, com os métodos psicoterápicos rasos, não alcançava a raiz do problema. Já, com as teorias de Freud, que tinham como hipótese encontrar as conexões psicológicas das diferentes neuroses, permitia a ele verificar uma nova possibilidade.

Segundo Handlbauer (2005), "há diversas versões contraditórias de como inicialmente os dois se encontraram [- a] maioria não foi devidamente comprovada até hoje" (p. 18). A mais conhecida, entretanto, remonta da época da publicação de Die Traumdeutung (Interpretação de Sonhos), por Freud, no periódico Neue Freie Presse. Apesar de receber muitas críticas, Adler posicionou-se a favor da teoria de Freud. Isto porque, sentiu e viu nesta teoria novas descobertas que abriam uma nova fase para o desenvolvimento da Psiquiatria e da Psicologia. Ao conhecer os métodos aplicados e tão bem exemplificados na Interpretação dos Sonhos, Adler experimentou alguns, modificando-os, pois acreditava que duas pessoas não poderiam usar métodos idênticos ao se colocarem em contato com os seres humanos.

Devido a sua reação positiva, em um cartão postal escrito à mão, o próprio Freud sugeriu que Adler se unisse ao círculo ou, como ficaria conhecida futuramente, à "Sociedade das Quartas-Feiras": "Uma vez por semana um grupo de psicoterapeutas reunia-se na casa de Freud para informar sobre seus trabalhos e estudos e para discutir problemas médicos, culturais e filosóficos à luz dos novos métodos" (Furtmüller, 1968, pp. 294-295).

No primeiro encontro, que ocorreu em outubro de 1902, observa-se que, segundo Stekel (1950, p. 115 como citado em Handlbauer, 2005), havia uma harmonia total entre os cinco integrantes: Sigmund 
Freud, Alfred Adler, Wilhelm Stekel, Max Kahane e Rudolf Reitler. Ainda, segundo a impressão de Stekel, "parecíamos pioneiros em uma terra recém-descoberta [...]" (p. 25).

Este primeiro grupo apesar de ser composto exclusivamente por médicos, não demorou muito para variar em peso de intelecto e personalidade; profissionais de outras áreas foram admitidos: escritores, acadêmicos de ciências humanas e educadores. Alguns usavam do impulso e das inspirações de Freud para investigações independentes, mas a maioria atuava estritamente sobre os conselhos do mestre. "Em uma nuvem de fumaça de tabaco e confortados por muitas xícaras de um forte café preto, tratavam de demolir um antigo mundo de pensamento e de construir um novo" (Furtmüller, 1968, p. 295); o que não significava que todas as discussões eram igualmente satisfatórias e interessantes.

Nesse sentido, tanto as posições quanto as publicações dos membros do grupo e as do próprio Freud, sempre passavam primeiro pelo processo de avaliação de uma discussão no círculo, para depois serem de fato expostas e/ou divulgadas. O que causava, em boa parte dos membros, uma certa fascinação especial: "um grupo pequeno e ousado, agora perseguido, mas destinado a conquistar o mundo" (Furtmüller, 1968, p. 295). Para Adler, entretanto, não existia essa questão emocional de fascinação, pois nunca sentiu-se membro de um grupo minoritário, pois "havia aprendido anos antes a ser membro de uma minoria na batalha contra opiniões estabelecidas e interesses criados. [...] Sua mente crítica sempre o fazia desconfiar de qualquer ideia que era aceita com demasiada ligeireza, apenas por esse fato" (Furtmüller, 1968, pp. 295-296).

Suas atividades no círculo eram estritamente objetivas: "queria e estava disposto a aprender, mas entendia que o que aprendia, 0 assimilaria a seu próprio modo de pensar e o usaria como um elemento em seu trabalho independente" (Furtmüller, 1968, p. 296). Tal posicionamento se dava porque Adler compartilhava da ideia de que os conhecimentos, as aprendizagens adquiridas durante os estudos deveriam ser compartilhados: o dar e o receber não egoísta, Ihe parecia a base da cooperação científica. Consequentemente, nunca estabeleceu um relacionamento morno com os membros do círculo ou com o próprio Freud.

No outono de 1906, começou a ficar evidente o primeiro movimento de "dissidência de Adler na 'Sociedade das Quartas-Feiras' [...], quando apresentou uma palestra a respeito da base orgânica das neuroses" (Handlbauer, 2005, p. 45), que daria origem, no ano de 1907, ao livro Studie über Minderwertigkeit von Organen (Estudo sobre a inferioridade dos órgãos). Uma monografia proveniente de sua prática e de seus estudos enquanto jovem médico. A respeito desta obra, Freud manifestou-se afirmando que, "muito do que Adler [dizia] poderia estar correto" (p. 55). 
Ainda no mesmo ano, quando Adler dedicou-se a falar a respeito do "sumário de uma teoria das neuroses", ficou ainda mais evidente a primeira indicação de que, "o Estudo não era simplesmente o resultado de um ativo interesse na patologia dos rins e de outros órgãos, e de que não se deveria limitar às bases orgânicas da neurose. Pelo contrário, Adler queria produzir uma nova teoria pioneira das neuroses" (Handlbauer, 2005, p. 57, grifo do autor). Uma teoria que introduzia pontos de vista sociológicos e sóciopsicológicos às discussões psicanalíticas. Uma teoria que revisava as ideias de Freud, descordando quanto à etiologia das neuroses.

De acordo com Handlbauer (2005), "Freud gostava do conceito de compensação. As ideias [...] acerca do deslocamento da energia compensatória provavelmente correspondiam com a maneira de pensar de Freud" (p. 60). Entretanto, somente reconheceria de fato os trabalhos de Adler, se este, segundo Holtz (1981 como citado em Handlbauer, 2005), "não atacasse o que para Freud era fundamental - a etiologia sexual das neuroses" (p. 60).

Nos encontros subsequentes, que ocorreram entre outubro de 1908 e junho de 1910, as diferenças teóricas entre Adler e Freud cresceram ainda mais significativamente.

A apresentação a respeito da base orgânica das neuroses foram as primeiras a indicar suas contrastantes opiniões que, mesmo assim, foram toleradas pelo grupo assim como por Freud. Mas, agora, o ambiente parecia reverter-se e esta crescente divisão em seus entendimentos teóricos tornar-se-ia conspícua em três específicas reuniões, nas quais Adler fez suas apresentações: em 3 de fevereiro de 1909 ("Um caso de rubor compulsivo"), em 2 de junho de 1909 ("A unicidade das neuroses") e em 23 de fevereiro de 1910 ("Hermafroditismo psíquico") (Handlbauer, 2005, p. 88).

A crise final deu-se, por fim, no verão de 1911, durante o período de recesso do grupo, quando Freud escreveu uma carta ao responsável pela publicação do Zentralblatt für Psychoanalyse (periódico fundado por Adler e Freud e no qual eram editores), "anunciando que já não podia mais ser responsável da edição juntamente com Adler, assim ele teria que escolher entre ambos" (Furtmüller, 1968, p. 300). Após o editor comunicar o conteúdo da carta, Adler renunciou tanto ao seu cargo de editor quanto o de presidente na Sociedade Psicanalítica de Viena.

Sem dúvida, Adler sentiu-se profundamente ofendido com a atitude de Freud e com a situação desagradável criada por ele. Em nenhum momento, Adler perdeu o controle. Pelo contrário, informou calmamente aos companheiros o que estava ocorrendo e agiu com extrema cautela e restrição frente às críticas de Freud.

Na primeira reunião da Sociedade das Quartas-Feiras, após o ocorrido, o próprio Freud, segundo Furtmüller (1968), apresentou uma moção afirmando que "os membros de qualquer sociedade fundada por Adler 
eram incompatíveis com os membros de seu grupo" (p. 300). O que gerou diversas controvérsias e nove dos membros, depois de agradecerem por tudo que tinham aprendido, abandonaram a reunião e formaram com Adler (presidente) uma nova associação, a Sociedade à Investigação Psicanalítica Livre.

\section{Da sociedade à investigação psicanalítica livre à psicologia individual}

Durante toda a sua vida Adler foi um trabalhador enérgico e incansável, mas não tanto como nos anos depois que deixou o grupo de Freud. Além dos pacientes que atendia de manhã até a tarde e algumas vezes estendiam-se à noite, Adler escrevia artigos, lia artigos de outros pesquisadores, comparecia às reuniões semanais no novo grupo, vez ou outra conversava com alguns membros que queriam falar com ele individualmente sobre algum problema ou alguma prática, lia e respondia cartas, dava atenção aos convidados do exterior, proferia conferências e cuidava de seus quatro filhos que estavam crescendo (Furtmüller, 1968).

A frenética intensidade de trabalho possibilitou, em 1912, a publicação de seu livro Über den nervösen Charakter (Sobre o caráter nervoso ou $O$ caráter neurótico), onde integrou todo o seu pensamento e todas as investigações ao longo de sua carreira, principalmente ao unificar as respostas à problemas específicos que vinha estudando.

Um exemplo desta integração de pensamento encontra-se em sua concepção de condição humana, que se origina do conceito alemão Gemeinschaftsgefühl, de difícil tradução, mas que é interpretado pelas expressões interesse social, sentimento social, sentimento de comunidade ou sentido social. Conceito este que, de acordo com Stein e Edwards (1998), demonstra o interesse social do indivíduo pelo plano afetivo desenvolvido, bem como pelo sentimento de sentir-se parte da raça humana e, como resultado, conseguir simpatizar-se com seus semelhantes humanos. Nas palavras de Adler (1968b), o sentimento de comunidade

[...] é uma forma de vida (Lebensform). [...] Isso não deve ser entendido como uma forma de vida superficial, como se não fosse nada mais que a expressão de um modo de vida adquirido mecanicamente. É muito mais. Não estou em condição de defini-lo de forma inequívoca, mas encontrei em um autor inglês uma frase que expressa claramente algo que poderia contribuir com nossa explicação: "Ver com os olhos de outro, ouvir com os ouvidos de outro, sentir com o coração de outro" (pp. 46-47). 
Em 1913, a Sociedade à Investigação Psicanalítica Livre muda seu nome para Psicologia Individual. Isto porque, primeiro, "Freud insistia em que o termo psicanálise devia ser reservado exclusivamente para as verdades e os erros que ele apoiava pessoalmente" (Furtmüller, 1968 , p. 318). E, segundo, porque era adequado que o nome adotado expressasse significativamente à ideia central da Psicologia de Adler: uma Psicologia que se referia a personalidade e que não via apenas as diferentes ações e ideias do indivíduo como causa de poderes psíquicos isolados, ou como motivados por certas experiências isoladas, mas, também, uma Psicologia que via as diferenças e/ou a unidade em relação com o todo no retrato psicológico do indivíduo.

Lembrando que o desenvolvimento da personalidade para Adler (1968a) é visto como um processo ativo e criativo, no qual as pessoas atribuem significado às experiências de vida que enfrentam e, dessa forma, não são vítimas passivas da hereditariedade ou do ambiente, mas sim construtores e intérpretes ativos de sua situação e/ou realidade. Dessa forma, "o indivíduo não se relaciona apenas com o mundo externo de uma maneira predeterminada, como se supõe frequentemente, mas, também, sempre segundo sua própria interpretação de si mesmo e de seu problema atual" (1968a, pp. 66$67)$.

Nem a herança, nem o meio ambiente determinarão a relação entre o indivíduo com o meio externo. Isto porque, para Adler (1968a), a herança somente dota o indivíduo de certas capacidades e o meio ambiente somente lhe dá certas impressões. Em suas palavras, o "modo individual de fazê-lo - ou [...] sua atitude perante a vida - é que determinará sua relação com o mundo externo" (pp. 66-67). Nesse sentido, se cada indivíduo produz significados e age singularmente, deve-se estudá-lo à luz de seu próprio desenvolvimento.

O nome escolhido, Psicologia Individual, gerou algumas objeções. A principal delas encontrava-se no fato de sugerir o estudo das reações psíquicas do homem isolado, individualmente. Mas, pelo contrário, a Psicologia Individual considerava que o indivíduo podia somente ser estudado e entendido em suas relações com os grupos sociais a qual vivia para, então, compreender sua unidade. Nas palavras de Furtmüller (1968), "o nome expressava muito mais sobre o sistema que cobria, do que muitos termos científicos podiam fazer" (p. 319). Ou, como colocado por Leal e Antunes (2015),

À sua época, e ainda nos atuais dias, [tendia-se] a entender [à] Psicologia Individual como uma Psicologia individualista, que se [limitava] a focar o sujeito [única e exclusivamente] em suas particularidades. Mas, pelo contrário, ao escolher o termo Psicologia Individual, Adler pautou-se no pressuposto de que, 
por ser o indivíduo (do latim individuus; IN = não e DIVIDUUS = divisível) uma unidade indivisível, é impossível estudá-lo isolado de sua totalidade e de sua unicidade, sem levar em consideração a realidade social a que pertence e sua influência na construção de sua personalidade. (Leal \& Antunes, 2015, p. 16).

Em 1914, Adler, juntamente com seu grupo, publicou o primeiro número da Zeitschrift für Individualpsychologie - meio de comunicação onde a voz do grupo seria ouvida continuamente e a atenção à nova Psicologia cresceria. Segundo Furtmüller (1968), "Não planejaram somente artigos para a Zeitschrift, mas também um número grande de livros, que logo colocaram-se a caminho" (p. 320). Com a chegada da Primeira Guerra Mundial, muita coisa mudou em suas vidas e, principalmente, no grupo, que passou a sentir os efeitos da guerra: "a maioria dos membros era suficientemente jovem para serem recrutados imediatamente. As reuniões semanais cessaram; a Zeitschrift deixou de existir. Alguns meses mais tarde, Adler também teve que vestir o uniforme de médico da armada" (Furtmüller, 1968, p. 320) - o que Ihe trouxe novos campos de atuação e estudo: o tratamento das neuroses de guerra, os assuntos mundiais, os problemas da personalidade humana e, principalmente, a retomada do conceito de sentimento de comunidade.

No primeiro período da República Austríaca, após o período de Guerra, Adler tomou parte ativa na política, sobretudo no Comitê de Trabalhadores do Primeiro Distrito de Viena, como vice-presidente. Entretanto, Adler não ambicionava sua ascensão na política. Pelo contrário, seus interesses passaram a ser fundamentalmente às atividades educacionais. Como descreveu Furtmüller (1968) a este respeito, parecia que o momento oferecia uma oportunidade que não deveriam deixar passar, principalmente porque "a cooperação parecia ainda mais possível, [e] os princípios básicos da reforma escolar de Viena, a respeito dos métodos de educação, tinham muito em comum com os ensinamentos da Psicologia Individual" (p. 328).

Com base neste novo interesse, o primeiro passo para concretizá-lo deu-se quando Adler aceitou o "convite para dar conferências regulares em Volksheim, o instituto de educação para adultos mais importante de Viena, naquele tempo" (Furtmüller, 1968, p. 327). O segundo passo, se deu quando Adler tornou-se membro da Faculdade de Professores, do Instituto Pedagógico da Cidade de Viena.

Pode-se dizer que, nesse período, Adler influenciou o pensamento e os métodos pedagógicos de muitos professores e, consequentemente, o desenvolvimento das escolas; principalmente porque os professores que assistiam suas conferências compreendiam que, primeiro, ao discutirem seus casos individuais, Adler Ihes ensinava um método para que utilizassem de suas próprias observações agregadas às 
informações obtidas com os pais, posteriormente. E, segundo, que a prática proposta dava ideias, hipóteses acerca do que estava acontecendo na mente da criança e como esta reagiria ao procedimento subsequente a que o professor a submeteria.

O contato com um grande número de professores durante suas conferências, juntamente com o fato de ser membro da Associação de Psicologia Individual de Professores, proporcionou a Adler, além da influência diretriz ao campo da educação, a formação do grupo Erziehungsberatungsstelle, que criou e estabeleceu um número significativo de clínicas de condução infantil nas escolas estatais, com o consentimento das autoridades escolares e de atendimento voluntário-gratuito.

As clínicas destinavam-se às crianças com problemas educacionais, encaminhadas por seus professores em comum acordo com os pais. O trabalho era conduzido com base nos princípios adlerianos: um professor e um psiquiatra, ambos dispostos a oferecer um conselho, nunca um método estereotipado; atuavam em conjunto, além de desenvolverem seus próprios métodos de atendimento, sobre uma base comum.

O próprio Adler trabalhava em uma dessas clínicas e o método que utilizava parecia, a princípio, um experimento ousado, mas com êxitos significativos: realizava a entrevista com a criança e com os pais, não em um espaço fechado e privado, mas sim em um auditório com um número considerável de pessoas observando-os. "A sessão começava com um informe oral ou escrito do professor que trouxera o caso à clínica. Depois, Adler analisava este informe e, a partir dele, traçava um desenho do caráter e dos problemas da criança e da situação familiar. Logo, seguiam as entrevistas [...]" (Furtmüller, 1968, p. 333).

A grande habilidade de Adler encontrava-se no fato de fazer com que a criança e os adultos se sentissem tão confiantes que acabavam esquecendo que estavam em um auditório e interagiam com ele como se estivessem a sós, em um consultório. O que não quer dizer que Adler facilitasse as coisas. Pelo contrário, como o tempo era precioso, gostava de chegar ao centro das dificuldades com suas primeiras perguntas e observações.

Em sua prática, Adler nunca deu um conselho autoritário. Fazia com que a criança estudasse o seu problema e lhe ajudava a estabelecer um plano para superar suas dificuldades; fixava uma data para uma entrevista posterior, onde a criança diria como havia funcionado o plano. Na última etapa, Adler dava um resumo, um informe aos professores e pais, tomando-o como um exemplo para a elucidação de problemas mais gerais e não somente como um problema particular.

Infelizmente, o trabalho com as clínicas de condução infantil chegou a um fim abrupto no ano de 1934, quando os austrofascistas 
derrotaram a República Austríaca pois tinham como um de seus primeiros objetivos, aniquilar a reforma escolar e todas as atividades conectadas a ela e implantar novas autoridades escolares.

\section{Os anos nos Estados Unidos}

Durante o período de mudanças do pós-Guerra, principalmente nos anos que antecederam a derrota da República Austríaca e a chegada de Hitler à Viena, Adler já havia direcionado boa parte de suas atividades para fora de seu país.

Primeiro porque "depois da guerra o interesse internacional em suas teorias fazia-se cada vez mais vivo e a rede de amigos e seguidores fora da Áustria tornava-se maior" (Furtmüller, 1968, p. 334). Segundo que, com as publicações da Zeitschrift cada vez mais a nível internacional, com um número extenso de colaboradores de muitos países, mais pessoas do estrangeiro, principalmente Inglaterra, Holanda e Estados Unidos, vinham à Viena para permanecer um curto período com Adler e seu círculo para conhecer mais sobre a Psicologia Individual. E, terceiro, como descreveu Furtmüller (1968), essas pessoas não eram turistas que em sua passagem queriam entrar em contato com "a última palavra em evolução intelectual"; mas sim, "trabalhadores sérios que ao regressarem a seus próprios países criavam centros de Psicologia Individual" (p. 334).

Nesse período, um de seus maiores desafios, apesar da extensa agenda de compromissos, foi o aprendizado da fala em língua inglesa - já lia em inglês -, para que pudesse conferir algumas de suas palestras na América do Norte. Apesar do medo inicial de não dominar tão bem o idioma, as conferências de Adler tiveram êxito e seu trabalho passou a se concentrar cada vez mais na América do Norte. Entre “1929-1937 foi catedrático na Universidade de Columbia e, a partir de 1932, professor convidado de Psicologia Médica na Faculdade de Medicina de Long Island" (Furtmüller, 1968, p. 337). Assim a questão da língua não fora impedimento algum para Adler; pelo contrário, assim como o fazia em alemão, Adler respondia a todos os questionamentos, bem como improvisava e fazia piadas em inglês.

Nos anos em que se dividiu entre a Europa e a América do Norte, Adler trabalhou infatigavelmente; não descansava nem em seus períodos de férias. Infelizmente, esse modo de viver, o levara à consequências sérias: seu coração começou a bater mais fraco, esgotar-se. E, como bom diagnosticador que era, Adler sabia. No dia 28 de Maio de 1937, em Aberdeen, na Escócia, em uma viagem para conferências em vários lugares da Europa, durante um passeio, Adler desmaiou repentinamente e morreu a caminho do hospital. 
Em uma homenagem final a Adler, nas últimas páginas de sua biografia (autorizada pelo próprio), Bottome (1952) resume sua vida da seguinte forma:

Adler perdeu sua Viena. Perdeu a fortuna que ganhou com um trabalho duro e contínuo. Perdeu o fruto de seu ensinamento nas escolas de Viena. Perdeu sua filha mais velha, uma das companheiras preferidas de seu espírito. Entretanto, ganhou mais corações e ajudou a mais pessoas a realizarem-se do que qualquer um de seus contemporâneos. Com sua própria vida deu ao mundo o exemplo mais fidedigno de sua ciência. Adler era o "ser humano completo" que ele queria ajudar a formar e, quando a morte the chamou, se foi "smiling, from the snare of this great world uncaught" (p. 336).

Afinal, para Adler (como citado em Bottome, 1952), a morte era um benefício à humanidade. Sem ela, não haveria progresso. Principalmente porque, "às pessoas que vivessem sempre, não somente desanimariam aos jovens, mas também lhes faltaria estímulo suficiente pra crer" (p. 330).

\section{Considerações Finais}

Ao chegar aqui e diante da breve síntese biográfica tecida ao longo deste artigo, foi possível observar a relação existente entre a teoria e todo o percurso histórico de Adler, ao longo de sua vida. Como descrito por ele próprio, "vocês verão com toda clareza a harmonia existente entre os fatos de minha infância e as opiniões que depois expressei em meus estudos sobre A inferioridades dos órgãos (1907) e em minha obra principal, Sobre o caráter nervoso [...]" (Adler como citado em Bottome, 1952, p. 53).

Um exemplo dessa relação, pode ser observado, primeiramente, na descrição que Adler realizou de seu próprio posicionamento em sua constelação familiar ou fraterna (Geschwisterreibe): ora sentindo-se inferior com relação ao seu irmão mais velho (o primogênito), ora ao perder o lugar de filho mais novo e mimado pelos pais, para seu irmão Richard. Lembrando que, a constelação familiar ou fraterna indica "a posição da criança dentro do grupo de irmãos, bem como os diversos modos de interação que comportam esta situação. Adler foi o primeiro a chamar a atenção a respeito deste fenômeno e destacar sua importância na análise biográfica do [indivíduo]" (Von Perfall, 1999, pp. 71-72).

Em um segundo momento, mais maduro e com sua teoria ainda mais consolidada, ao observar a relação entre seus próprios filhos. Em suas palavras, "meus filhos menores, Kurt e Nelly, [...] [sofreram] 
com suas posições na constelação familiar, bem como, sem dúvida, com o fato de que o pai não dispunha de tanto tempo para dedicar-se a eles como havia se dedicado às filhas mais velhas" (como citado em Bottome, 1952, p. 126). Creia, ainda, que Kurt sofreu ainda mais, "por estar abaixo de suas irmãs mais velhas, ambas garotas altamente desenvolvidas e valentes, bem como Nelly, a mais nova, sabia da importância de ser a 'Pulgarcita' da família” (p. 126, grifo da autora). Afinal, para o teórico, a posição de um único filho homem entre filhas mulheres, pode causar um desenvolvimento desfavorável da identidade sexual e, consequentemente, da personalidade. Isto porque, ao crescer em um meio rodeado de mulheres, o filho homem pode "se ver [ou] dominado por elas [...] e desenvolver traços femininos, ou, impulsionado a rebelar-se contra elas, desenvolver traços masculinos para acentuar sua diferença e superioridade" (Von Perfall, 1999, p. 75).

Outro exemplo, encontra-se na clareza que Adler tinha a respeito de seus sentimentos frente às inseguranças que sentia em relação aos irmãos, às dificuldades enfrentadas no período escolar e, principalmente, às debilidades ocasionadas pela condição física frágil enfrentada na infância. Tais sentimentos estão relacionados à inferioridade que estes causavam nele diante dos percalços da vida. Em alemão Ohnmachtsgefühl (sentimento de impotência) ou Keitsgefühl (sentimento de menos valia) que, indica "a sensação de desamparo, de fraqueza e de dependência de situações ou pessoas que levam o indivíduo à buscar apoio, força e segurança para poder desenvolver-se adequadamente no mundo" (Von Perfall, 1999, pp. 330-331).

[...] a base da vida da alma começa sempre com um sentimento de inferioridade mais ou menos profundo e, este sentimento, é "a força motriz, o ponto que inicia e desenvolve todas as aspirações da criança e que Ihe impõe um objetivo de espera de tranquilidade e de segurança para o futuro, mostrando-Ihe o caminho que parece mais adequado para a sua realização" (Adler como citado em Von Perfall, 1999, pp. 71-72).

Encontram-se aqui, os primeiros indícios de se desenvolver, sob o influxo do sentimento de inferioridade e do propósito dele originado, a compensação ou a supercompensação. Destacando que, a compensação é o processo, segundo Adler, que levará o indivíduo a busca de segurança, apoio, melhoramento, êxito e perfeição. A compensação, em suas palavras, "tem a tarefa de cobrir o menos, indo de baixo para cima" (como citado em Von Perfall, 1999, p. 61). Já, a supercompensação está relacionada tanto ao complexo de inferioridade, que impede o desenvolvimento da personalidade e de 
adaptação do indivíduo ao seu meio, quanto ao de superioridade, que apresenta uma forte inclinação do indivíduo em se achar único, tornando-se egoísta. "Ambos [os casos, se] constituem formas exageradas do sentimento de inferioridade e o desejo de superioridade" (p. 62)

No caso de Adler, os indícios de compensação são nitidamente passíveis de serem observados: a superação das debilidades causadas tanto pelo raquitismo quanto pela pneumonia, principalmente quando decide-se pela medicina como possibilidade de ajudar o outro a não passar pelo que passou; o sentir-se desafiado pelo professor para compensar suas dificuldades nos cálculos aritméticos; o notável destaque que conquistou com a profissão e que era motivo de admiração de seus irmãos (com exceção do mais velho que, até a morte de Adler, nunca conseguiram estabelecer um bom diálogo); a superação das adversidades teóricas enfrentadas durante a Sociedade das Quartas-Feiras e a criação de uma nova forma de ver e fazer Psicologia, entre outras.

Por fim, a breve biografia de Adler, permitiu observar que um dos seus principais conceitos, o de sentimento de comunidade, foi sendo construído desde as primeiras relações estabelecidas com os colegas de rua e da escola, passando pelo relacionamento que estabelecia com seus pacientes no consultório e, chegando, à preocupação com a reconstrução social da educação de seu país. Afinal, para Adler o sentimento de comunidade era o único que permitia ao indivíduo ver bem com os seus olhos, ouvir com seus ouvidos e sentir com seu coração. Consequentemente, conquistar o espírito de solidariedade, os laços afetivos e as relações íntimas e duradouras necessários a formação da personalidade.

\section{Referências}

Adler, A. (1993). El carácter neurótico. Barcelona: Paidós.

Adler, A. (1968a). Tipología del enfrentamiento a los problemas de la vida. In Superioridad e Interés Social - Una colección de sus últimos escritos (pp. 66-69). México: Fondo de Cultura Económica.

Adler, A. (1968b). Breves comentarios sobre razón, inteligencia y debilidad mental. In: Superioridad e Interés Social - Una colección de sus últimos escritos (pp. 46-52). México: Fondo de Cultura Económica.

Bottome, P. (1952). Alfred Adler: Apóstol de la Libertad. Barcelona: Luis Miracle.

De Certeau, M. (2010). A escrita da História (2a ed.). Rio de Janeiro: Forense Universitária. 
Furtmüller, C. (1968). Alfred Adler: un ensayo biográfico de Carl Furtmüller. In ADLER, A. Superioridad e Interés Social - Una colección de sus últimos escritos (pp. 269-341). México: Fondo de Cultura Económica.

Handlbauer, B. (2005). A Controvérsia Freud-Adler. São Paulo: Madras.

Leal, D. \& Antunes, M. A. M. (2015). Compensação e deficiência no pensamento de Alfred Adler (1870-1937). Memorandum, 29, 13-33.

Stein, H. T. \& Edwards, M. E. (1998). Classical Adlerian Theory and Practice. Alfred Adler Institute of San Francisco \& Northwestern Washington. Recuperado em 25 abril 2016 de http://www. adlerian.us/theoprac. htm

Von Perfall, C. A. (1999). Diccionario de Psicología Individual. Madrid: Editorial Sintesis.

\section{Endereço para correspondência \\ Daniela Leal}

Centro Universitário Moura Lacerda - CUML

Rua Padre Euclídes, 995, Campos Elísio, CEP 14080-200, Ribeirão Preto - SP, Brasil Endereço eletrônico: daniela.leal@mouralacerda.edu.br

Marina Massimi

Universidade de São Paulo - USP

Av. Bandeirantes, 3900, Vila Monte Alegre, CEP 14040-900, Ribeirão Preto - SP, Brasil

Endereço eletrônico: mmassimi@yahoo.com.br

Recebido em: 06/09/2016

Reformulado em: 27/11/2016

Aceito em: $27 / 11 / 2016$

\section{Notas}

* Doutora e Mestre em Psicologia da Educação pela PUC-SP. Atualmente é professora no PPGE - Mestrado, do Centro Universitário Moura Lacerda, coordenadora do NIEPED - Núcleo Interáreas de Estudos e Pesquisas em Educação e Diversidade (CUML) e Pós-doutoranda pelo Departamento de Psicologia da FFCLRP- USP. Tem experiência de pesquisa nas áreas de Educação e Psicologia, com ênfase em Educação Especial e Inclusiva, História da Educação Especial e História da Psicologia. Membro associada da Sociedade Brasileira de História da Psicologia (SBHP); da Associação Brasileira de Pesquisadores em Educação Especial (ABPEE) e da Associação Nacional de Pós-Graduação e Pesquisa em Educação (ANPED).

** Possui graduação em Psicologa - Università degli Studi di Padova (1979), mestrado (1985) e doutorado (1989) em Psicologia (Psicologia Experimental) pela Universidade de São Paulo. Atualmente é professora titular da Universidade de São Paulo. Tem experiência de pesquisa na área de Psicologia, com ênfase em História da Psicologia, atuando principalmente nos seguintes temas: história da psicologia científica; história dos saberes psicológicos na cultura brasileira, saberes psicológicos dos jesuítas. Presidente da Sociedade Brasileira de História da 
Psicologia de 2013 a 2015 e atualmente Vice-Presidente. Membro da Academia Ambrosiana (Milão). Coeditora da Revista Memorandum: Memória e História em Psicologia. 